\title{
SISTEM INFORMASI GEOGRAFIS PEMETAAN TEMPAT KOS DI SAMARINDA BERBASIS WEB
}

\author{
Natalia Bunga Kambuno \\ Politeknik Pertanian Negeri \\ Samarinda Teknologi Rekayasa \\ Perangkat Lunak Manajemen \\ Pertanian \\ Samarinda, Kalimantan Timur \\ nataliabungak@gmail.com
}

\author{
Wahyuni Eka Sari \\ Teknologi Rekayasa Perangkat \\ Lunak \\ Politeknik Pertanian Negeri \\ Samarinda Manajemen Pertanian \\ Samarinda, Kalimantan Timur \\ wahyunisari52@gmail.com
}

\author{
Dawamul Arifin \\ Teknologi Geomatika \\ Politeknik Pertanian Negeri \\ Samarinda Manajemen Pertanian \\ Samarinda, Kalimantan Timur \\ dawam.arifin00@gmail.com
}

\begin{abstract}
Abstrak-Penelitian ini dilatarbelakangi oleh ketersediaan informasi yang sangat terbatas mengenai lokasi tempat kos yang menyebabkan mahasiswa baru cenderung tidak memiliki informasi yang akurat dan relevan sehingga tidak mengetahui lokasi mana yang memiliki tempat kos dengan biaya terjangkau, dekat tempat kuliah, tempat kerja, atau lembaga pendidikan. Oleh karena itu tujuan dari penelitian ini adalah membangun sebuah aplikasi sistem informasi geografis pemetaan tempat kos berbasis web yang informatif dan menarik sehingga dapat memudahkan para pengguna khususnya mahasiswa baru yang ingin melakukan pencarian kos disekitar area Perguruan Tinggi seperti Politeknik Pertanian Negeri Samarinda (POLITANI), Politeknik Negeri Samarinda (POLNES), dan Universitas Mulawarman 1 (UNMUL) di Jl. Kuaro, Gn. Kelua, Kec. Samarinda Ulu, Kota Samarinda, Kalimantan Timur. Hasil penelitian Sistem Informasi Geografis Pemetaan Tempat Kos berbasis Web ini dapat memberikan informasi untuk mempermudah pengguna menemukan lokasi kos dan informasi lainnya seperti fasilitas, harga, nomor HP, alamat, dan ukuran kamar kos.
\end{abstract}

Kata Kunci- Sistem Informasi Geografis, Kos, Samarinda.

\section{PENDAHULUAN}

Seiring dengan jumlah penduduk yang semakin bertambah dari waktu ke waktu dan terjadinya proses perpindahan penduduk yang sangat cepat dalam kehidupan masyarakat menyebabkan kebutuhan akan tempat tinggal juga meningkat secara proporsional.

Pada umumnya mahasiswa dalam mencari tempat kos banyak bertanya kepada teman, ataupun bertanya langsung kepada pemilik tempat kos. Ketika mereka bertanya pada pihak tersebut biasanya mereka bertanya tentang fasilitas tempat kos, biaya tempat kos tiap bulan / tahun , dan jarak tempuh antara tempat kos dengan tempat tujuan. Hambatan yang terjadi adalah waktu yamg dibutuhkan bisa sangat lama karena harus mengunjungi tempat dan membandingkan dengan pilihan yang lain. Oleh karena itu dibutuhkan sistem yang lebih efisien agar mahasiswa dapat menentukan pilihan tempat kos yang sesuai dengan pilihan mereka dengan waktu yang relatif lebih singkat.

Sistem pencarian kos dapat diintegrasikan dengan teknologi informasi, salah satu sistem yang dapat diterapkan adalah Sistem Informasi Geografis pencarian lokasi kos. SIG memiliki kegunaan dalam membantu pekerjaan yang erat dengan bidang-bidang spasial dan geinformasi seperti menvisualkan data spasial berupa atribut, modifikasi warna, bentuk, untuk verifikasi data, penyimpanan data, perubahan data dan updating data, memanajemen data dan pertukaran data, manipulasi data, pemanggil data, presentasi data dan analisa data.

Kemajuan teknologi Informasi geografis semakin dibutuhkan oleh banyak kalangan misalnya informasi jarak antar daerah, lokasi, fasilitas dan banyak informasi lainnya. Informasi tersebut diperlukan untuk berbagai keperluan seperti penelitian, pengembangan, perancangan wilayah serta manajemen sumber daya alam. Karena adanya geografis ini dapat membantu penyajian suatu informasi yang lebih interaktif, dimana pengguna dapat mengakses informasi geografis yang lengkap hanya dengan menggunakan komputer, web-browser dan jaringan internet. Maka untuk mendapatkan informasi itu semua diperlukan Geographical Information System (GIS) atau yang dikenal dengan Sistem Informasi Geografis (SIG).

Dengan kemampuan yang dimiliki Sistem Informasi Geografis, sistem ini dianggap tepat dimanfaatkan untuk mendapatkan tempat kos yang di inginkan, apalagi jika Sistem Informasi Geografis ini digabungkan dengan teknologi berbasis web, maka waktu yang di butuhkan akan semakin efisien.

\section{TINJAUAN PUSTAKA}

\section{A. Sistem Informasi Geografis}

Sistem Informasi Geografis atau Geographical Information System (GIS) merupakan computer yang berbasis pada sistem informasi yang digunakan untuk memberikan bentuk digital dan analisa terhadap permukaan geografi bumi (Prahasta, 2002).

Sistem Informasi Geografis adalah sistem komputer yang digunakan untuk memanipulasi data geografi. Sistem ini diimplementasikan dengan perangkat keras dan 
perangkat lunak computer yang berfungsi untuk akuisisi dan verifikasi data, kompilasi data, penyimpanan daya, perubahan data dan updating data, memanajemen data dan pertukaran data, manipulasi data, pemanggil data, presentasi data dan analisa data.

Sistem Informasi Geografis sebagai suatu sistem yang berbasiskan komputer yang digunakan untuk menyimpan dan memanipulasi informasi-informasi geografis. Sistem Informasi Geografis dirancang untuk mengumpulkan, menyimpan, dan menganalisis objek-objek dan fenomena dimana lokasi geografis merupakan karakteristik yang penting atau kritis untuk dianalisis. Jika definisi sistem informasi geografis diperhatikan maka, sistem informasi geografis dapat diuraikan menjadi beberapa subsistem berikut:

1. Data Input : Subsistem ini bertugas untuk mengumpulkan, mempersiapkan dan menyimpan data spasial dan artibutnya dari berbagai sumber.

2. Data Output : Subsistem ini menampilkan atau menghasilkan keluaran (termasuk mengekspornya keformat yang dikendaki) seluruh atau sebagian basisdata (spasial) baik dalam bentuk softcopy maupun hardcopy.

3. Data Management : Subsistem ini mengorganisasikan baik data

spasial maupun tabel-tabel atribut terkait ke dalam sebuah basisdata sedemikian rupa sehingga mudah dipanggil kembali atau di-retrieve, di update, dan di edit.

4. Data Manipulation dan Analysis : Subsistem ini menentukan informasi- informasi yang dapat dihasilkan oleh sistem informasi geografis. Selain itu, subsistem ini juga melakukan manipulasi dan pemodelan data untuk menghasilkan informasi yang diharapkan.

Dari pengertian yang telah dipaparkan dapat ditarik kesimpulan bahwa Sistem Informasi Geografis merupakan suatu sistem untuk memasukkan, mengelola (penyimpanan dan pemanggilan data), manipulasi dan analisis, serta menyajikan informasi secara geografis berikut dengan depenelitian dari keadaan geografis suatu wilayah untuk digunakan sebagai bahan.

Sistem informasi geografis dapat merepretasikan real world (dunia nyata) di atas monitor komputer sebagaimana lembaran peta dapat merepresentasikan dunia nyata di atas kertas. Tetapi, sistem informasi geografis memiliki kekuatan lebih dan fleksibelitas dari pada lembaran peta kertas. Peta merupakan representasi grafis dari dunia nyata, objek-objek yang direpresentasikan di atas peta disebut unsur peta atau map features (contohnya adalah sungai, kebun, jalan, dan lain-lain). Karena peta mengorganisasikan unsur-unsur berdasarkan lokasi-lokasinya, peta sangat baik dalam memperlihatkan hubungan atau relasi yang dimiliki oleh unsur- unsurnya (Prahasta, 2002).

Sistem informasi geografis menyimpan semua informasi deskriptif unsur-unsurnya sebagai atribut-atribut di dalam basisdata. Kemudian, sistem informasi geografis membentuk dan menyimpannya di dalam tabel-tabel (relasional). Setelah itu, sistem informasi geografis menghubungkan unsur- unsur di atas dengan tabel-tabel yang bersangkutan. Dengan demikian, atribut-atribut ini dapat diakses melalui lokasilokasi unsur-unsur peta, dan sebaliknya unsur-unsur peta juga dapat diakses melalui atribut-atributnya. Karena itu, unsur-unsur tersebut dapat dicari dan ditemukan berdasarkan atribut-atributnya.

Sistem informasi geografis menghubungkan sekumpulan unsur-unsur peta dengan atribut-atributnya di dalam satuansatuan yang disebut layer. sungai, bangunan, jalan, laut, batas-batas administrasi, perkebunan, dan hutan merupakan contoh-contoh dari layer. Kumpulan dari layer-layer ini akan membentuk basisdata sistem informasi geografis. Dengan demikian, perancangan basisdata merupakan hal yang esensial di dalam sistem informasi geografis. Rancangan basisdata akan menentukan efektifitas dan efisiensi prosesproses masukan, pengelolaan, dan keluaran sistem informasi geografis.

Sistem informasi Geografis memiliki perbedaan pokok dengan sistem informasi lain. Perbedaan ini menjadi ciri karakteristiknya. Pada sebuah sistem informasi selain SIG, basis data atributal adalah focus dari pekerjaan sistem, sedangkan SIG meningkakan data atributal dengan data spasial. Mengingat sumber data sebagian besar dari data peindraan jauh baik citra satelit maupun citra foto, maka teknologi sistem informasi geografis (SIG) erat kaitannya degan teknologi pengindraan jauh. Akan tetapi, pengindraan jauh bukanlah satu-satunya ilmu pendukung bagi sistem ini. Sumber data lain berasal dari hasil survei terrestrial (uji lapangan) dan data sekunder lain seperti sensus, catatan, dan laporan yan terpercaya.

\section{B. Pengertian Kos}

Kos merupakan jasa yang menawarkan sebuah kamar atau tempat untuk ditinggali dengan sejumlah pembayaran tertentu untuk setiap periode tertentu (umumnya pembayaran per bulan atau per tahun) (Hastiyanto, 2011).

Fungsi kos dirancang untuk memenuhi kebutuhan hunian yang bersifat sementara dengan sasaran pada umumnya adalah mahasiswa dan pelajar yang berasal dari luar kota atau luar daerah, namun tidak sedikit pula kos ditempati oleh masyarakat umum yang tidak memiliki rumah pribadi dan menginginkan berdekatan dengan lokasi beraktifitas.

Oleh karena itu, fungsi kos dapat dijabarkan sebagai berikut :

a. Sebagai sarana tempat tinggal sementara bagi mahasiswa yang pada umumnya berasal dari luar daerah selama masa studinya.

b. Sebagai sarana tempat tinggal sementara bagi masyarakat umum yang bekerja dikantor atau yang tidak memiliki rumah tinggal agar berdekatan dengan lokasi kerja.

c. Sebagai sarana pembentukan kepribadian mahasiswa untuk lebih disiplin, mandiri dan bertanggung jawab. 


\section{WebGIS}

WebGIS merupakan aplikasi geographic information system (GIS) yang dapat diakses secara online melalui internet / web. Pada konfigurasi WebGIS ada server yang berfungsi sebagai MapServer yang bertugas memproses permintaan peta dari client dan kemudian mengirimkannya kembali ke client. Dalam hal ini pengguna / client tidak perlu mempunyai software GIS, hanya menggunakan internet browser seperti Internet Explorer, Mozilla Fire Fox, atau Google Chrome untuk mengakses informasi GIS yang ada di server (Frianto, 2015).

\section{Google Maps API}

Google Maps API yang paling populer di internet.

Pencatatan yang dilakukan pada bulan Mei 2010 ini menyatakan bahwa $43 \%$ mashup (aplikasi dan situs web yang menggabungkan dua atau lebih sumber data) menggunakan Google Maps API . Beberapa tujuan dari penggunaan Google Maps API adalah untuk melihat lokasi, mencari alamat, mendapatkan petunjuk mengemudi dan lain sebagainya. Hampir semua hal yang berhubungan dengan peta dapat memanfaatkan Google Maps.

Google Maps diperkenalkan pada februari 2005 dan merupakan revolusi bagaimana peta di dalam web, yaitu dengan membiarkan user untuk menarik peta sehingga dapat menavigasinya. Solusi peta ini pada saat itu masih baru dan membutuhkan server khusus. Beberapa saat setelahnya, ada yang berhasil men-hack Google Maps untuk digunakan di dalam webnya sendiri. Hal ini membuat Google Maps mengambil kesimpulan bahwa mereka membutuhkan API dan pada Juni 2005, Google Maps API dirilis secara publik (Svennerberg, 2010).

\section{E. PHP (Hypertext Preprocessor)}

PHP merupakan bahasa berbentuk script yang di tempatkan dalam server dan di proses di server. Selain itu juga PHP merupakan salah satu dari sekian banyak bahasa pemrograman HTML (Hypertext Markup Language). Dibuat oleh Rasmus Lerdorf diawali dengan membuatnya sebagai personal project dan disempurnakan oleh group six of developers dan lahir kembali dengan nama PHP. Secara khusus, PHP dirancang untuk membentuk web dinamis. Artinya, PHP dapat membentuk suatu tampilan berdasarkan permintaan. PHP memiliki kemampuan yang baik dalam hal perhitungan matematika, dalam hal informasi jaringan $e$ mail dan regular expression. Selain itu PHP juga mampu sebagai interface dengan database secara baik, support dengan bermacam-macam database server seperti MySQL, ORACLE, Sysbase.

PHP dapat berjalan dengan web server yang berbeda dan dalam sistem operasi yang berbeda pula. PHP dapat berjalan di sistem operasi UNIX, Windows97, WindowsNT. PHP adalah bahasa scripting yang menyatu dengan HTML untuk membuat halaman web yang dinamis dan dijalankan pada server side. Artinya semua sintaks yang kita berikan akan sepenuhnya dijalankan pada server tetapi disertakan pada dokumen HTML sedangkan yang dikirim ke browser hanya hasilnya saja. Kode PHP diawali dengan tanda lebih kecil
$(<)$, dan diakhiri dengan tanda lebih besar (>) (Prihatna, 2005).

\section{F. JavaScript}

JavaScript adalah bahasa scripting yang popular di internet dan dapat bekerja di sebagian besar browser populer seperti Internet Explorer (IE), Mozila Firefox, Netscape dan Opera. Kode Javascript dapat disisipkan dalam halaman web menggunakan tag script (Sunyoto, 2007).

Beberapa hal tentang Javascript:

1. Javascript didesain untuk menambah interaktif suatu web.

2. Javascript merupakan sebuah scripting.

3. Bahasa scripting merupakan bahasa pemograman yang ringan.

4. Javascript berisi kode yang dijalankan di komputer (web browser).

5. Javascript biasanya disisipkan (embedded) dalam halaman HTML.

6. Javascript adalah bahasa interpreter (yang berarti skrip dieksekusi tanpa proses kompilasi).

7. Setiap orang dapat menggunakan Javascript tanpa membayar lisensi.

\section{METODE PENELITIAN}

\section{A. Metode Penelitian}

Tahapan pembuatan aplikasi Sistem Informasi Geografis Pemetaan Tempat Kos di Samarinda Berbasis web ini menggunakan metode waterfall, model ini melakukan pendekatan secara sistematis atau berurutan, dalam membangun suatu alur prosedur penelitian ini dapat diliat pada Gambar 1.

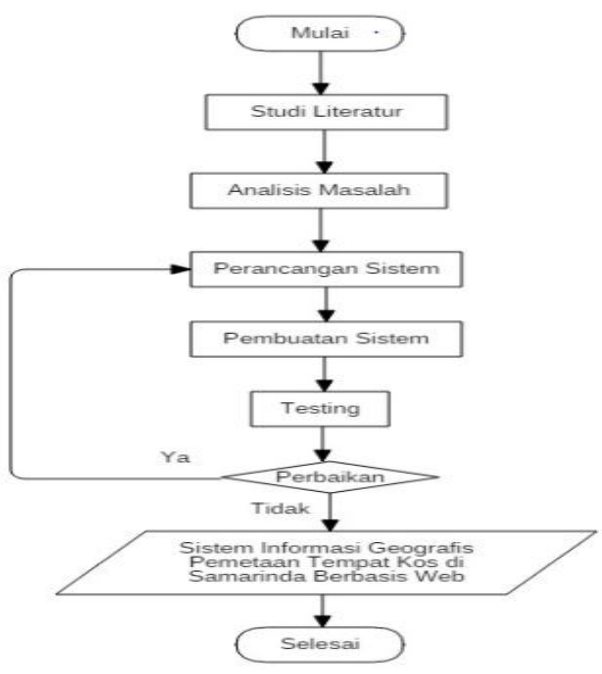

Gambar 1. Metode Penelitian

1. Studi Literatur

a) Studi Pustaka

Pembuatan dan pengembangan aplikasi ini mengambil bahan referensi seperti Jurnal yang terkait.

b) Observasi 
Dengan melakukan pengamatan serta menganalisa secara langsung terhadap data-data yang dimiliki oleh kos. Kegiatan ini diperlukan guna mendapatkan data-data yang akan mendukung proses penelitian langsung dari sumbernya.

c) Wawancara

Wawancara yang dilakukan kepada pemilik kos guna mengetahui informasi yang disediakan oleh kos sehingga dapat memberikan data yang bersangkutan dengan penelitian.

2. Analisis Masalah

Pada tahap ini dilakukan proses analisa bahwa monitoring disetiap kos masih menggunakan cara manual, oleh karena itu dibuatlah Sistem informasi Berbasis WebGIS dengan objek tempat kos agar memudahkan pengerjaan dan Monitoring Secara Online dan Realtime.

3. Perancangan Sistem

Perancangan sistem membantu dalam perangkat keras (hardware) dan sistem persyaratan dan juga membantu dalam mendefinisikan arsitektur sistem secara keseluruhan.

4. Pengerjaan Sistem (Implementasi)

Penjelasan pengerjaan sistem yang diakukan adalah untuk membuat suatu aplikasi sistem informasi pemetaan dengan web yang berjalan dengan baik yaitu dengan langkah pertama sediakan peta dari google maps, website yang berisikan tentang lokasi kos, dan menggabungkan google maps dengan website sehingga menjadi suatu sistem informasi geografis pemetaan berbasis web.

5. Pengujian (Testing)

Pada tahap ini di lakukan proses pengujian sistem guna mengetahui apakah sistem berjalan dengan baik atau tidak, jika ada masalah pada sistem maka akan dilakukan perancangan sistem ulang untuk memperbaiki permasalahan yang terjadi.

B. Analisa Data

Analisa data menjelaskan proses pengolahan arus data spasial dan non spasial sampai dengan penggabungan SIG dan Web, dapat diliat pada Gambar 2 .

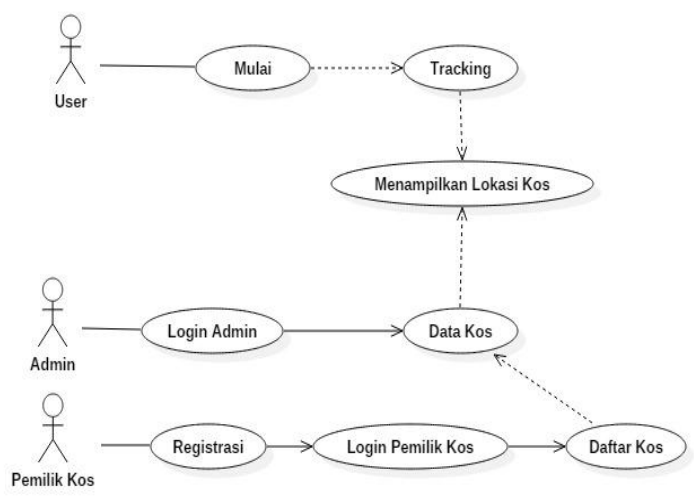

Gambar 2. Rancangan Pembuatan Analisa Data
Disini user/pengguna akan mulai menggunakan aplikasi dengan mencari lokasi kos yang akan dituju. Kemudian untuk admin harus melakukan login agar mendapatkan akses untuk menampilkan, mengubah, dan menghapus data kos. Untuk setiap pemilik kos yang ingin mendaftar harus melakukan registrasi agar mempunyai akses dilogin agar bisa mendaftarkan kos.

\section{Rancangan User Interface}

\section{Home}

Tampilan Home akan menampilkan halaman awal aplikasi yang menampilkan navigasi untuk mengakses berbagai menu yang disediakan dalam aplikasi, dapat dilihat pada Gambar 3.

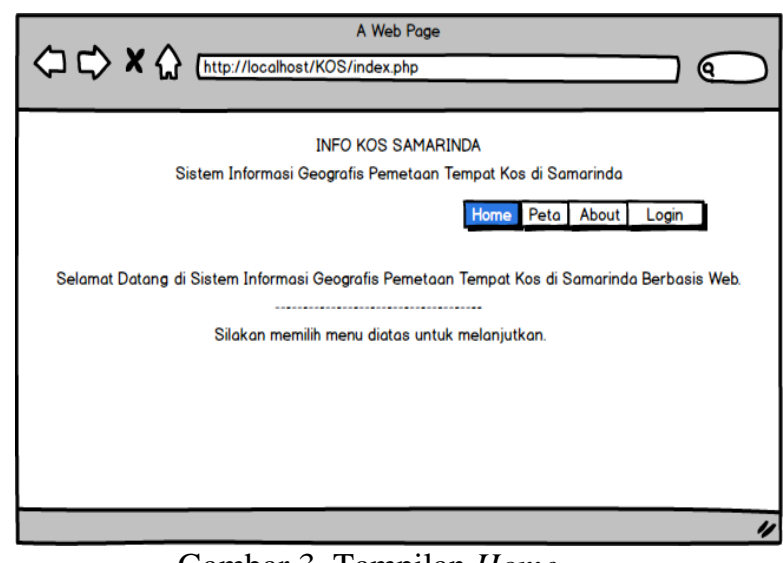

2. Peta

Tampilan Peta akan menampilkan peta samarinda dan didalamnya terdapat marker kos yang tersebar diarea Perguruan Tinggi seperti Politeknik Pertanian Negeri Samarinda (POLITANI), Politeknik Negeri Samarinda (POLNES), dan Universitas Mulawarman 1 (UNMUL) di Jl. Kuaro, Gn. Kelua, Kec. Samarinda Ulu, Kota Samarinda, Kalimantan Timur, dapat dilihat pada Gambar 4.

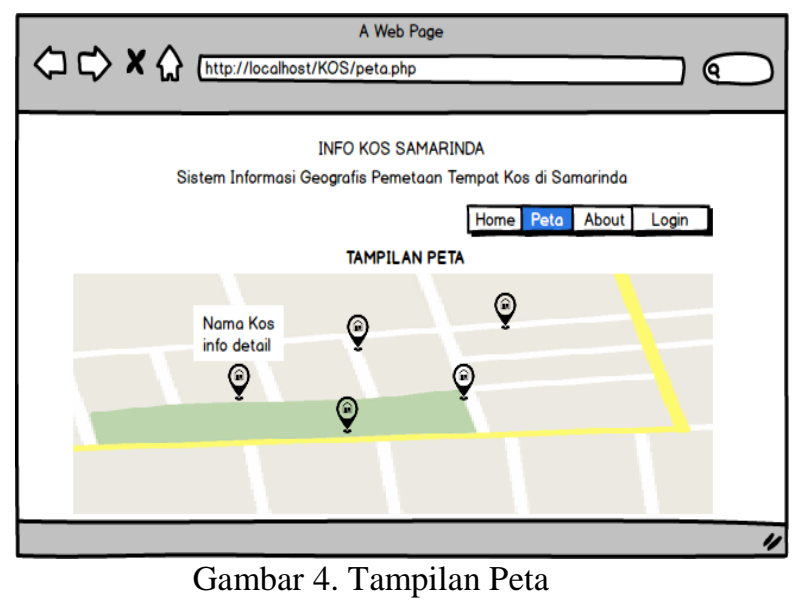

3. About

Pada tampilan About akan menampilkan informasi pemilik aplikasi, dapat dilihat pada Gambar 5. 


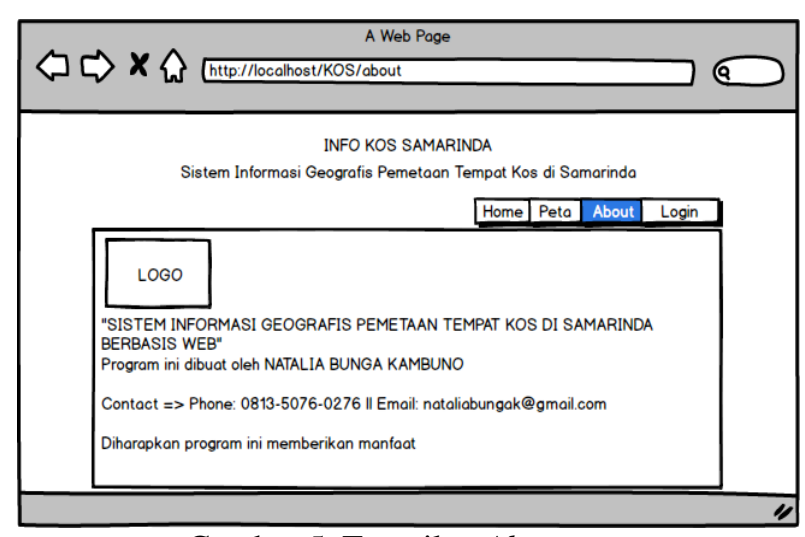

4. Login

Gambar 5. Tampilan About

Pada tampilan Login akan menampilkan username dan password untuk Admin dan Pemilik Kos (jika sudah mendaftar), dapat dilihat pada Gambar 6.

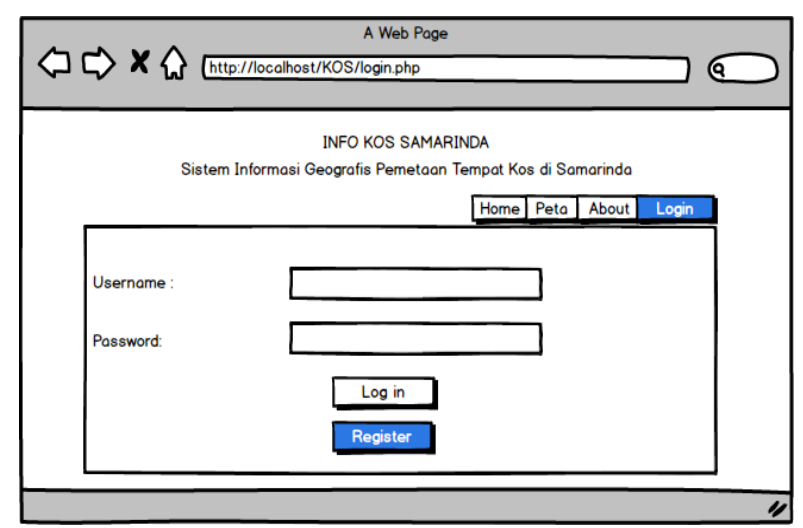

Gambar 6. Tampilan Login

5. Register

Pada tampilan register, pemilik kos harus mendaftar agar mendapatkan akses untuk mengelola data, dapat dilihat pada Gambar 7.

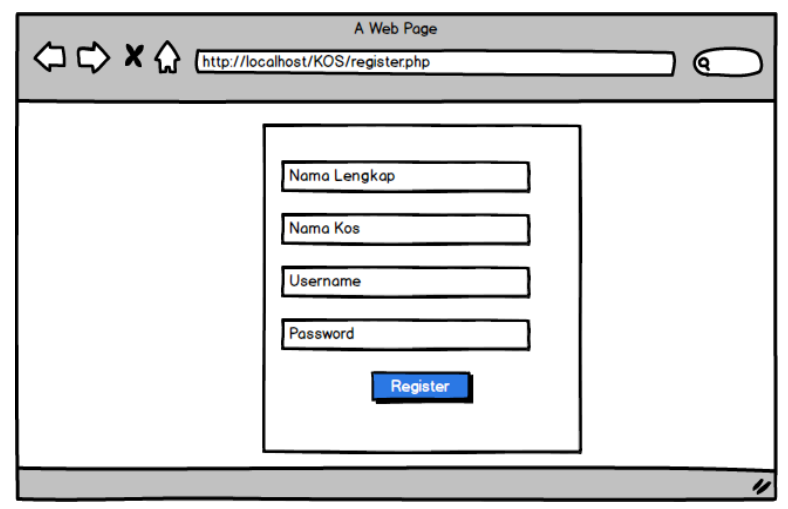

Gambar 7. Tampilan register

6. Data Kos

Pada halaman data kos, akan menampilkan tabel data yang berisi data kos yang tersedia seperti nama kos, kategori, fasilitas, harga, no. HP, alamat, keterangan dan juga ada pilhan button seperti tambah, edit, hapus data kos, dan detail lokasi kos. Dapat dilihat pada Gambar 8.

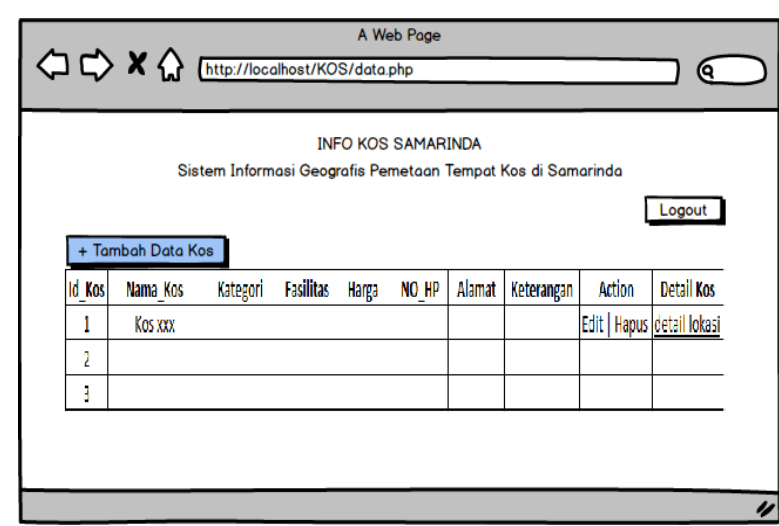

Gambar 8. Tampilan Data Kos

\section{HASIL DAN PEMBAHASAN}

\section{a. Tampilan Home}

Pada halaman depan terdapat tampilan menu yaitu menu Peta, menu about, menu login, dan menu register. Dapat dilihat pada Gambar 9.

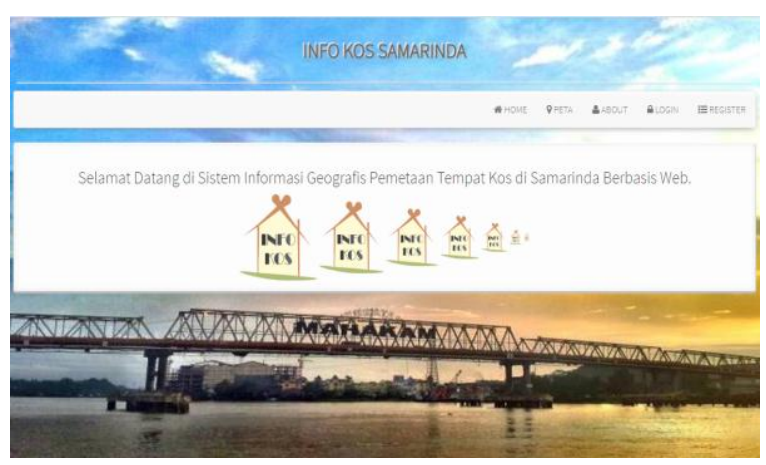

Gambar 9. Tampilan Home

b. Tampilan Peta

Pada tampilan peta, pengguna dapat melihat beberapa titik lokasi kos dan dapat memilih salah satu dari titik lokasi tersebut untuk melihat info detail kos dengan cara meng-klik pada icon marker kos, dan akan muncul dalam bentuk jendela (info window), dan juga terdapat filter seperti memilih harga kos dari paling murah sampai paling mahal dan dapat memilih kos berdasarkan ukuran kamar dari ukuran paling kecil sampai ukuran paling besar. Dapat dilihat pada Gambar 10.

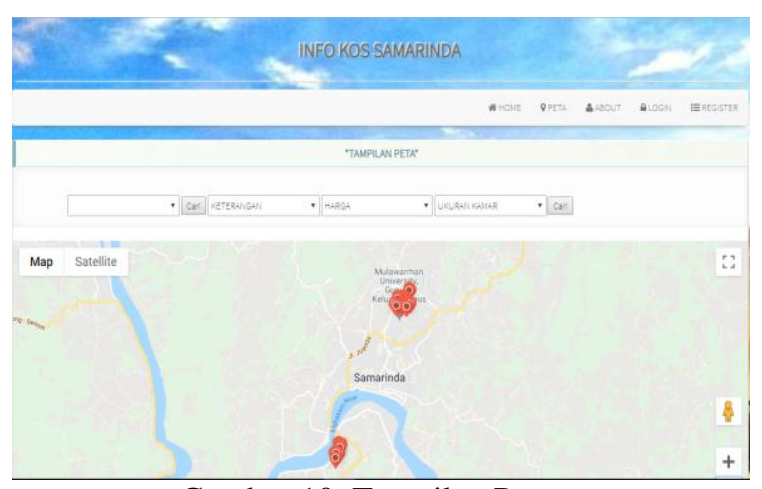

Gambar 10. Tampilan Peta 
Pada tampilan detail kos, pengguna dapat melihat informasi yang telah tersedia dan foto kos. Dapat dilihat pada Gambar 11.

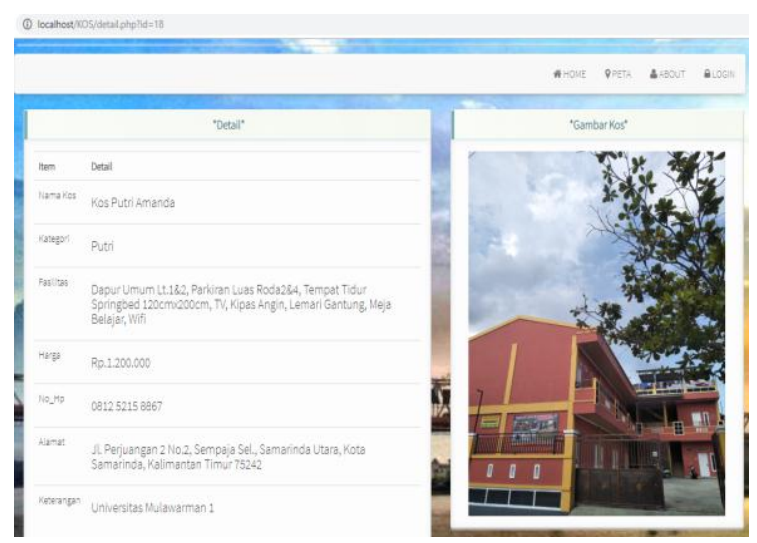

Gambar 11. Tampilan Detail kos

c. Tampilan About

Pada tampilan about, pengguna dapat melihat Informasi seperti nomor handphone dan email. Dapat dilihat pada Gambar 12.

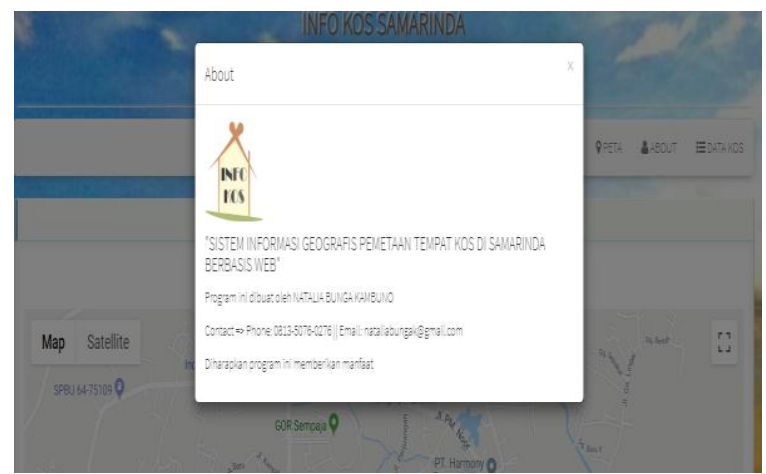

Gambar 12. Tampilan About

d. Tampilan Login

Pada tampilan login terdapat Username dan Password untuk Admin dan Pemilik Kos (jika sudah mendaftar), untuk tampilan login admin dapat dilihat pada Gambar 13.

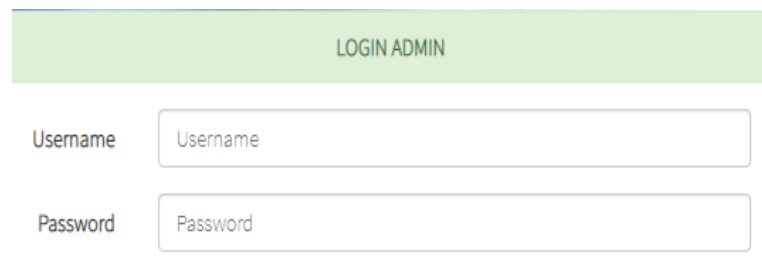

\section{Login}

Gambar 13. Tampilan Login Admin

Untuk tampilan login pemilik kos dapat dilihat pada Gambar 14.

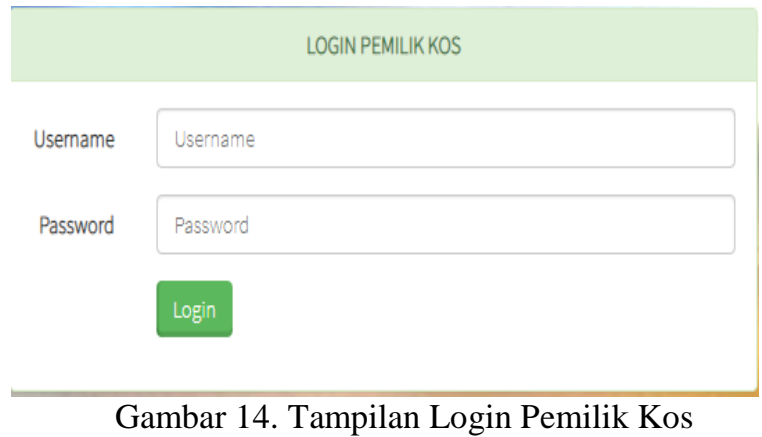

e. Tampilan Register

Pada tampilan register, pemilik kos harus mendaftar agar mendapatkan akses username dan password untuk mengelola data, dapat dilihat pada Gambar 15.

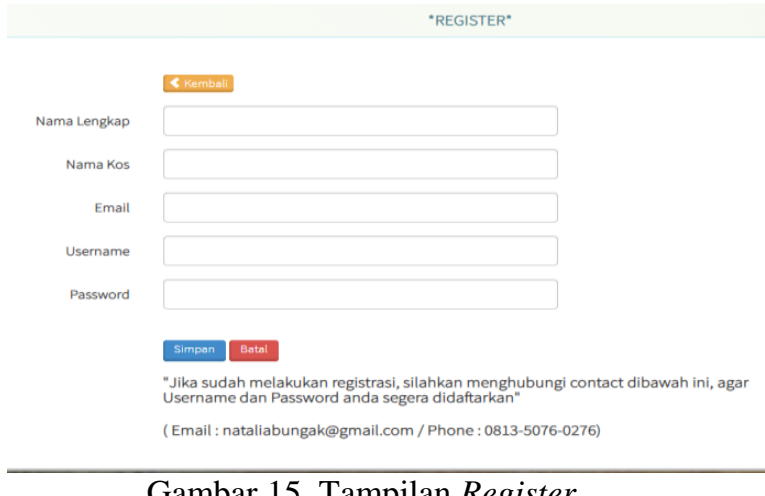

Gambar 15. Tampilan Register

f. Tampilan Data Kos

Pada halaman data kos, menampilkan tabel data yang berisi data kos yang tersedia seperti nama kos, kategori, fasilitas, harga, no. HP, alamat, dan keterangan. Dapat dilihat pada Gambar 16.

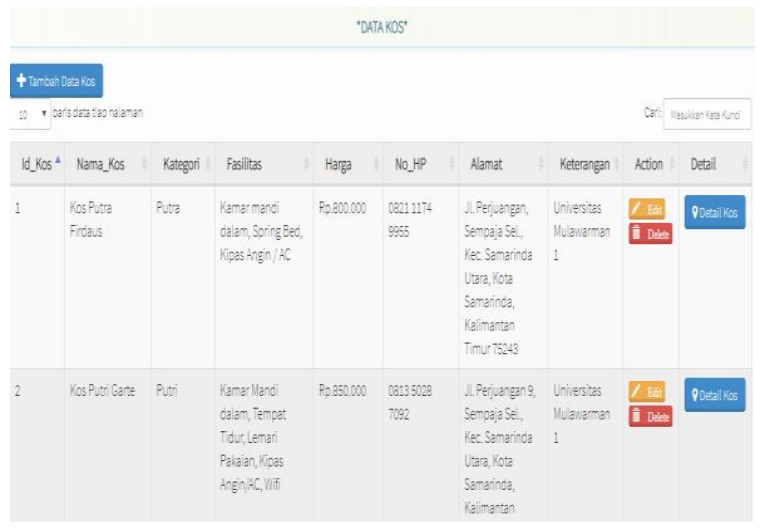

Gambar 16. Tampilan Data Kos

g. Tampilan Tambah Data Kos

Pada halaman ini untuk menambahkan data, admin dan pemilik kos harus memasukan Nama Kos, Kategori, Fasilitas, Harga, No. HP, Alamat, Katerangan, latitude, dan longitude. Terdapat button simpan dan batal. Dapat dilihat pada Gambar 17. 


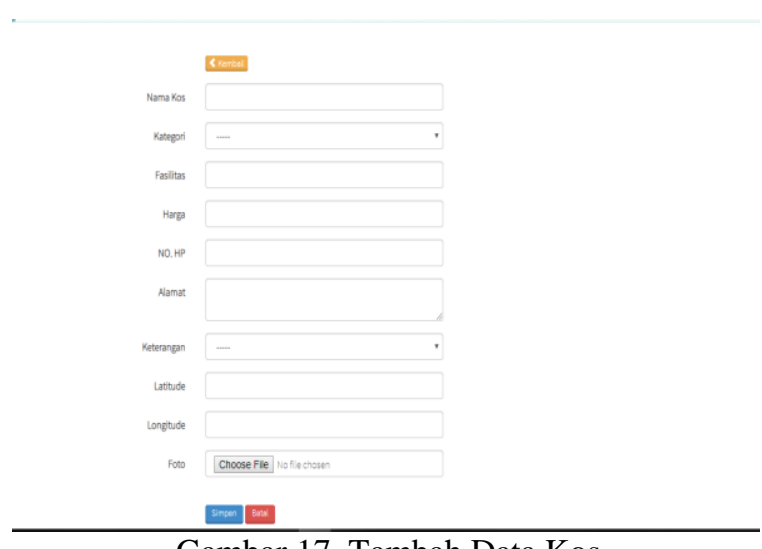

Gambar 17. Tambah Data Kos

h. Tampilan Edit Data Kos

Pada halaman ini untuk mengedit data, data yang sudah ada hanya perlu diubah jika terdapat kesalahan. Dapat dilihat pada Gambar 18.

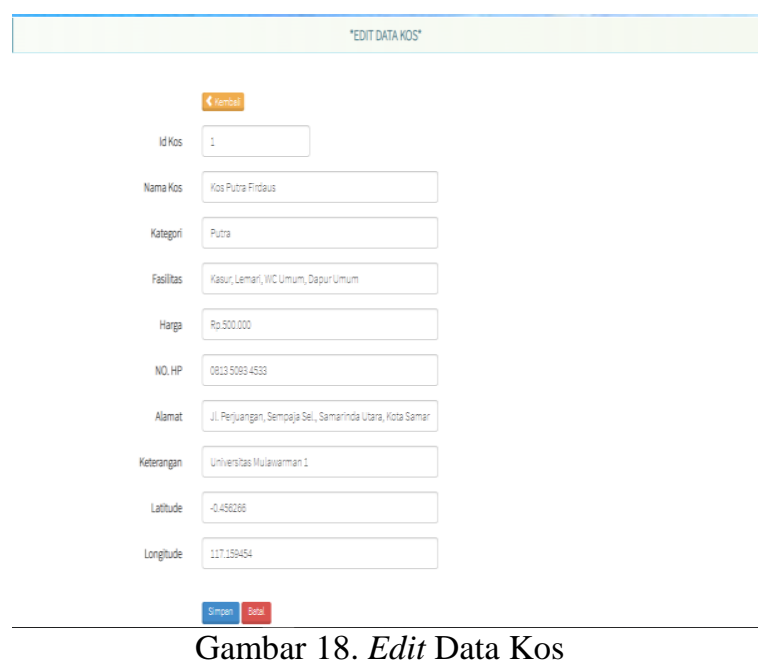

\section{KESIMPULAN}

Dalam pembuatan aplikasi sistem informasi geografis pemetaan tempat kos berbasis web didapatkan hasil untuk mempermudah pengguna menemukan lokasi kos. Seperti terdapat ada tiga filter pilihan pencarian perguruan tinggi seperti Politeknik Pertanian Negeri Samarinda (POLITANI), Politeknik Negeri Samarinda (POLNES), dan Universitas Mulawarman 1 (UNMUL) di J1. Kuaro, Gn. Kelua, Kec. Samarinda Ulu, Kota Samarinda, Kalimantan Timur. Terdapat filter untuk mencari kos dengan harga paling murah sampai paling mahal, dan terdapat filter untuk mencari ukuran kamar kos dari ukuran yang kecil, sedang dan besar. Aplikasi sistem informasi geografis pemetaan tempat kos berbasis web ini dapat menampilkan info detail seperti fasilitas, harga, nomor HP, alamat, dan ukuran kamar kos. Jadi pengguna akan lebih mudah menerima informasi yang akurat dan foto setiap kos.

Diharapkan aplikasi Sistem Informasi Geografis Pemetaan Tempat Kos Berbasis Web yang telah dibuat agar bisa ditingkatkan dengan berbasis android agar lebih mudah digunakan. Diharapkan tampilan aplikasi ini dibuat agar lebih menarik.

\section{DAFTAR PUSTAKA}

Frianto R. 2015. Aplikasi Sistem Informasi Geografis Berbasis WebGis Pemetaan Tempat Masjid di Pangkalpinang. Informatika, Kepulauan Babel.

Hastiyanto F. 2011. Pengertian Kos, Kontrak dan Sewa, Lampung: Penerbit Rubrik Bahasa.

Kadir, A. 2002. Pemrograman Web mencakup : HTML, CSS, Java Script \& PHP. Yogyakarta : Andi Offset.

Kosasi S. 2014. Sistem Informasi Geografis Pemetaan Tempat Kost Berbasis Web. Pontianak, Kalimantan Barat. 172 CSRID Journal Vol. 6. No. 3.

Prahasta, Eddy. 2002. Konsep-Konsep Dasar Sistem Informasi Geografis. Bandung: Informatika.

Ramadhani S., Anis U., dan Masruro S.T. 2013. Rancang Bangun Sistem Informasi Geografis Layanan Kesehatan Di Kecamatan Lamongan Dengan PHP MySQL. Lamongan. Jurnal Teknika Vol. 5, No. 2.

Riyanto, 2010, Sistem Informasi Penjualan Dengan PHP dan MySQL, Gava Media, Yogyakarta

Rochmah N. 2015. Sistem Informasi Geografis Tempat Praktek Dokter Spesialis Di Provinsi D.I. Yogyakarta Berbasis Web. Yogyakarta. Jurnal Ilmiah Ilmu Komputer Vol. 10, No.1.

Sunyoto, Andi 2007. Ajax Membangun Web dengan Teknologi Asynchronouse Javascript \& XML. Yogyakarta: Penerbit Andi Offset.

Svennerberg, G. 2010. Beginning Google Maps API 3. Apress. United States of America.

Wibowo J., Awaluddin M., dan Amarrohman F.J. 2017. Pembuatan Basis Data Spasial Tempat Indekos Berbasis Web di Area Kampus Universitas Negeri Sebelas Maret. Semarang. Jurnal Geodesi Undip Vol. 6, No. 4. 